\title{
UJI PEMANFAATAN TEKNOLOGI ELEKTROPLATING PADA PRODUK PANDAI BESI SEBAGAI UPAYA PENINGKATAN KUALITAS DAN DAYA SAING
}

\author{
Ahmad Mubin ${ }^{1}$
}

\begin{abstract}
The research of application of electroplating technology testing at Pandai Besi product as means to increase of quality and competitiveness had done, this research aimed to make reparation of production process and to applied electroplating technology in finishing process, until can adding to decorative properties and resistence of corrosion at product and to detrmine cost addition because that treatment.

According to the result of the data analysis by using two way Analysis of Variance (Anova) then continued by Least Square Difference $\left(\mathrm{LSD}_{0,05}\right)$ testing, can be seen that variation finishing process and variation of cooling media factors shows very significant difference toward specimen corrosion rate and there is interaction between both factors. From the result of continuation test by using $\mathrm{LSD}_{0,05}$ resulted the lowest corrosion rate (the best treatment) is $\mathrm{A} 3 \mathrm{~B} 1$ (chrom plating with water and "seer") combination.

Production cost (variable cost only) calculation result shows very high rising, until influence on determination of product selling price and marketting. Finishing process of chrom plating addition estimated to increase amount of $77 \%$ from production cost.
\end{abstract}

\section{Key Words : electroplating technology, quality and competitive}

\section{PENDAHULUAN}

\section{Dalam kondisi perekonomian} negara yang belum sepenuhnya normal dan masih tingginya angka pengangguran, maka sebagai alternatif jalan keluar adalah pemberdayaan usaha kecil menengah (UKM) yang jumlahnya terus meningkat dan tersebar di daerah perdesaan maupun di perkotaan, melalui upaya peningkatan kualitas produk dan daya saing pasar.

Salah satu UKM yang sangat memerlukan perhatian yaitu para pengrajin pandai besi yang sebagian besar masih menggunakan teknologi konvensional, sehingga kualitas produk kurang mempunyai daya saing dan jangkauan pemasarannyapun sangat terbatas.

Kenyataan di lapangan, diperoleh bahwa produk yang dihasilkan cepat mengalami korosi jika lapisan minyak yang dioleskan pada proses finishing telah hilang atau setelah produk tersebut digunakan. Oleh karena itu, harus dilakukan upaya peningkatan kualitas produk tersebut, misalnya dengan penerapan teknologi pelapisan krom (electroplating) sehingga dapat mencegah terjadinya korosi dan juga dapat memperbaiki penampilan produk. Dari uraian diatas, maka perlu dilakukan penelitian mengenai uji pemanfaatan teknologi elektroplating pada produk pandai 
besi sebagai upaya peningkatan kualitas dan daya saing.

\section{TINJAUAN PUSTAKA}

\section{Pelapisan Logam}

Pelapisan logam merupakan suatu proses metalurgy yang banyak melibatkan proses kimia.

\section{Jenis-Jenis Pelapisan Logam}

Macam-macam cara pelapisan logam dapat

dikelompokkan menjadi :

1. Pelapisan logam dengan logam lain secara listrik.

2. Pelapisan logam dengan logam lain tanpa listrik.

3. Pelapisan logam dengan bahan oksida secara listrik.

4. Pelapisan logam dengan bahan oksida tanpa listrik.

\section{Sifat Pelapis Krom}

Ion kromo atau krom bervalensi dua merupakan zat pereduksi kuat dan yang paling stabil ialah krom valensi tiga atau disebut kromi oksida. Krom tidak dapat ditemukan dalam keadaan murni, tetapi didapatkan dalam bentuk krom teroksidasi

Proses pelapisan krom banyak digunakan karena beberapa faktor kelebihan dibanding proses pelapisan yang lain. Sifat khas lapisan krom antara lain;
a. Keras dan tahan aus
b. Tahan terhadap korosi
c. Tahan panas
d. Tingkat gesekan yang rendah.

\section{Proses Pelapisan Krom}

Proses pelapisan saat ini dikenal ada dua macam yaitu :

a. Pelapisan krom mengkilap (dekoratif chromium plating). Pelapisan krom dekoratif ini umumnya tipis dan hanya berfungsi untuk memperindah benda kerja.

b. Pelapisan krom keras (hard chromium plating). Pelapisan krom keras ini biasanya digunakan untuk industri dan merupakan pelapisan krom yang tebal. Krom ini banyak digunakan karena memiliki kombinasi sifat-sifat yang menguntungkan, yaitu tahan terhadap panas, aus, korosi dan koefisien gesek yang rendah.

Proses pelapisan krom keras pada dasarnya sama dengan proses lapis listrik lainnya, yaitu dilakukan dalam suatu rangkaian yang sekurang-kurangnya terdiri atas satu anoda, katoda dan larutan elektrolit.

\section{Korosi}

Korosi didefinisikan sebagai kerusakan atau penurunan mutu logam karena bereaksi dengan lingkungannya. Secara umum, korosi juga dapat difahami sebagai reaksi kimia yang terjadi pada sejumlah logam ataupun logam campuran pada kondisi yang tidak sesuai yang menyebabkan terjadinya penipisan, pengikisan, kerusakan atau lubang-lubang pada logam tersebut. 


\section{Laju Korosi}

Laju korosi logam uniform logam dapat diukur dalam beberapa cara. Cara yang paling umum yaitu mengukur kehilangan berat sampel tertentu yang ditempatkan dalam lingkungan korosif selama waktu tertentu dan menyatakan kehilangan berat ini dalam satuan kehilangan berat per satuan luas per satuan waktu.

$$
\begin{aligned}
& \text { mmpy }=87,6 \frac{\mathrm{W}}{\text { D.A.T }} \\
& \mathrm{W}=\text { kehilangan berat }(\mathrm{mg}) \\
& \mathrm{D}=\text { densitas material }\left(\mathrm{gr} / \mathrm{cm}^{3}\right) \\
& \mathrm{A}=\text { luas spesimen }\left(\mathrm{cm}^{2}\right) \\
& \mathrm{T}=\text { waktu percobaan }(\mathrm{jam})
\end{aligned}
$$

\section{Pengaruh Lingkungan}

Lingkungan yang dapat mempengaruhi laju korosi antara lain :

\section{$>$ Oksigen}

$>$ Kecepatan aliran (effect of velocity)

$>$ Temperatur

$>$ Konsentrasi media korosif

$>$ Galvanic coupling

\section{Pencegahan Korosi}

Pencegahan korosi dapat dilakukan dengan beberapa cara antara lain :

$>$ Pemilihan material

> Peningkatan kemurnian logam

Tabel ringkasan ANAVA dua faktor.

\section{> Pengubahan lingkungan korosif \\ > Pemakaian pelindung/pelapisan \\ > Proteksi katoda dan anoda \\ $>$ Penambahan inhibitor}

\section{METODOLOGI PENELITIAN}

\section{Jenis Penelitian}

Jenis penelitian yang dilakukan adalah eksperimental yaitu penelitian yang dilakukan dengan mengadakan manipulasi terhadap objek penelitian.

\section{Variabel}

Sebagai variabel bebas adalah macam proses finishing dan macam media pendingin pada proses produksi pisau dapur di pandai besi, sedangkan variabel terikatnya yaitu laju korosi dalam media korosif.

\section{Metode Pengumpulan Data}

Data yang diperlukan meliputi, macam dan spesifikasi produk, tahapan proses produksi, laju korosi dan peningkatan biaya akibat adanya proses pelapisan krom.

\section{Teknik Analisa Data}

Untuk percobaan korosi, data yang sudah dikumpulkan dianalisa dengan menggunakan Analisa Varian (ANAVA) dua faktor atau klasifikasi ganda dan uji lanjutan.

\begin{tabular}{|c|c|c|c|c|c|c|}
\hline $\begin{array}{l}\text { SUMBER } \\
\text { VARIASI }\end{array}$ & DB & JK & KT & F hit. & \multicolumn{2}{|c|}{ F tab. } \\
\hline Perlakuan A & $\mathrm{a}-1$ & $\mathrm{JKA}$ & $\mathrm{JKA} / \mathrm{dba}$ & $\mathrm{KTA} / \mathrm{KTG}$ & & \\
\hline Perlakuan B & $\mathrm{b}-1$ & $\mathrm{JKB}$ & $\mathrm{JKB} / \mathrm{dbb}$ & $\mathrm{KTB} / \mathrm{KTG}$ & & \\
\hline Interaksi & $(\mathrm{a}-1)(\mathrm{b}-1)$ & $\mathrm{JK}(\mathrm{AB})$ & $\mathrm{JK}(\mathrm{AB}) / \mathrm{dbab}$ & $\mathrm{KT}(\mathrm{AB}) / \mathrm{KTG}$ & & \\
\hline Galat & $\mathrm{N}-\mathrm{ab}$ & $\mathrm{JKG}$ & $\mathrm{JKG} / \mathrm{dbg}$ & & & \\
\hline Total & $\mathrm{N}-1$ & $\mathrm{JKT}$ & & & & \\
\hline
\end{tabular}


HASIL DAN PEMBAHASAN

\section{Data Kehilangan berat spesimen dan laju} korosi

Dari percobaan korosi diperoleh data kehilangan berat spesimen dan selanjutnya dapat dihitung laju korosinya sebagaimana dalam tabel 1 dan tabel 2 berikut ini :

Tabel 1

Data kehilangan berat (mg) spesimen

\begin{tabular}{|c|c|c|c|c|c|}
\hline \multirow{2}{*}{$\begin{array}{l}\text { PERLAKUAN } \\
\text { FINISHING }\end{array}$} & \multirow{2}{*}{$\begin{array}{c}\text { MEDIA } \\
\text { PENDINGIN }\end{array}$} & \multicolumn{2}{|c|}{ ULANGAN } & \multirow{2}{*}{ JUMLAH } & \multirow{2}{*}{$\begin{array}{l}\text { RATA- } \\
\text { RATA }\end{array}$} \\
\hline & & 1 & II & & \\
\hline \multirow{4}{*}{ Al } & B1 & 229,7 & 105,9 & 335,6 & 167,8 \\
\hline & B2 & 50,4 & 98,0 & 148,4 & 74,2 \\
\hline & B3 & 30,1 & 29,8 & 59,9 & 30,0 \\
\hline & B4 & 59,7 & 62,0 & 121,7 & 60,9 \\
\hline \multirow{4}{*}{ A2 } & B1 & 176,2 & 156,1 & 332,3 & 166,2 \\
\hline & B2 & 39,3 & 49,5 & 88,8 & 44,4 \\
\hline & B3 & 37,2 & 12,5 & 49,7 & 24,9 \\
\hline & B4 & 41,2 & 78,4 & 119,6 & 59,8 \\
\hline \multirow{4}{*}{ A3 } & B1 & 22,7 & 18,6 & 41,3 & 20,7 \\
\hline & B2 & 27,1 & 22,4 & 49,5 & 24,8 \\
\hline & B3 & 22,2 & 18,2 & 40,4 & 20,2 \\
\hline & $\mathrm{B} 4$ & 50,3 & 38,9 & 89,2 & 44,6 \\
\hline
\end{tabular}

Keterangan

A1 : Finishing Kasar

A2 : Finishing Halus

A3 : Pelapisan Krom
B1 : Pendingin Air + Air Seer

B2 : Pendingin Air Tanpa Seer

B3 : Pendingin $\mathrm{Oli}+$ Air Seer

B4 : Pendingin Oli Tanpa Seer

Tabel 2

Data Laju korosi spesimen (mmpy)

\begin{tabular}{|c|c|c|c|c|c|}
\hline \multirow{2}{*}{$\begin{array}{l}\text { PERLAKUAN } \\
\text { FINISHING }\end{array}$} & \multirow{2}{*}{$\begin{array}{c}\text { MEDIA } \\
\text { PENDINGIN }\end{array}$} & \multicolumn{2}{|c|}{ ULANGAN } & \multirow{2}{*}{ JUMLAH } & \multirow{2}{*}{$\begin{array}{l}\text { RATA- } \\
\text { RATA }\end{array}$} \\
\hline & & 1 & II & & \\
\hline \multirow{4}{*}{$\mathrm{A} 1$} & B1 & 1,087 & 0,501 & 1,588 & 0,794 \\
\hline & B2 & 0,239 & 0,464 & 0,703 & 0,352 \\
\hline & B3 & 0,142 & 0,141 & 0,283 & 0,142 \\
\hline & B4 & 0,283 & 0,294 & 0,577 & 0,289 \\
\hline \multirow{4}{*}{ A2 } & B1 & 0,834 & 0,739 & 1,573 & 0,787 \\
\hline & B2 & 0,186 & 0,234 & 0,420 & 0,210 \\
\hline & B3 & 0,176 & 0,059 & 0,235 & 0,118 \\
\hline & B4 & 0,195 & 0,371 & 0,566 & 0,283 \\
\hline \multirow{4}{*}{$\mathrm{A} 3$} & B1 & 0,107 & 0,088 & 0,195 & 0,098 \\
\hline & B2 & 0,128 & 0,106 & 0,106 & 0,053 \\
\hline & B3 & 0,105 & 0,086 & 0,191 & 0,096 \\
\hline & $\mathrm{B} 4$ & 0,238 & 0,184 & 0,422 & 0,211 \\
\hline
\end{tabular}




\section{Biaya Produksi}

1. Biaya produksi meliputi :

a. Biaya bahan baku

Bahan baku yang digunakan adalah campuran besi dan baja dengan harga per kilogram masing-masing $\mathrm{Rp}$. 2.000 ,- dan Rp. 13.000,-. Untuk satu buah produk diperlukan biaya bahan baku sebesar Rp. 750,-.

b. Biaya Tenaga kerja sebesar Rp. $1.700,-/$ produk. c. Biaya Arang, dan lain-lain sebesar Rp. 350,-/produk

d. Biaya Pegangan Kayu sebesar Rp. 200 ,-/produk

e. Biaya Cincin Besi sebesar Rp. 200,/produk

f. Biaya transportasi sebesar Rp. 50,/produk

g. Biaya Pelapisan krom sebesar Rp. $2.500,-/$ produk

\section{Percobaan Korosi}

Tabel jumlah dari Tabel 2 diatas adalah sebagai berikut :

\begin{tabular}{|c|c|c|c|c|c|}
\hline & $\mathbf{B 1}$ & $\mathbf{B 2}$ & $\mathbf{B 3}$ & $\mathbf{B 4}$ & TOTAL \\
\hline $\mathbf{A 1}$ & 1,589 & 0,703 & 0,284 & 0,576 & 3,152 \\
\hline $\mathbf{A 2}$ & 1,573 & 0,420 & 0,235 & 0,566 & 2,794 \\
\hline $\mathbf{A 3}$ & 0,196 & 0,234 & 0,191 & 0,422 & 1,043 \\
\hline TOTAL & 3,358 & 1,357 & 0,71 & 1,564 & 6,989 \\
\hline
\end{tabular}

Selanjutnya dianalisa dengan faktor atau dua arah dan diperoleh menggunakan Analisa Varian (Anava) dua sebagaimana dalam Tabel 3 :

Tabel 3

Ringkasan Analisa Varian (ANAVA) Dua Arah

\begin{tabular}{||l|c|c|c|c|c|c|}
\hline \multicolumn{1}{|c|}{ SUMBER VARIASI } & JK & DB & KT & F HIT. & \multicolumn{2}{c|}{ F TAB. } \\
\hline Perlakuan Finishing, A & & & & & $\mathbf{0 , 0 5}$ & $\mathbf{0 , 0 1}$ \\
\hline Media Pendingin, B & 0,320 & 2 & 0,160 & $8,507^{* *}$ & 3,89 & 6,93 \\
\hline Interaksi & 0,644 & 3 & 0,215 & $11,415^{* *}$ & 3,49 & 5,95 \\
\hline Galat & 0,385 & 6 & 0,064 & $3,412^{*}$ & 3,00 & 4,82 \\
\hline Total & 0,226 & 12 & 0,019 & & & \\
\hline \hline
\end{tabular}

Hasil analisa varian sebagaimana dalam Tabel 3 memperlihatkan bahwa perlakuan variasi finishing dan variasi media pendingin masing-masing Fhit $\gg$ Ftab. pada taraf nyata 0,05 maupun taraf sangat nyata 0,01 dan menunjukkan adanya interaksi antara keduanya (Fhit $>$ Ftab.). Dengan demikian dapat dinyatakan bahwa laju korosi spesimen berbeda sangat nyata atau dengan kata lain bahwa :

a. Perlakuan finishing yang berbeda sangat berpengaruh terhadap laju korosi spesimen.

b. Media pendingin yang berbeda sangat berpengaruh terhadap laju korosi spesimen.

c. Ada interaksi antara keduanya. 


\section{Uji Lanjutan dengan BNT}

Analisa varian untuk percobaan korosi menunjukkan adanya pengaruh sangat nyata antara perlakuan finishing dan media pendingin yang berbeda terhadap laju korosi spesimen dan menunjukkan adanya interaksi antara kedua faktor tersebut, maka untuk memperoleh perlakuan terbaik terhadap ketahanan korosi spesimen dilanjutkan uji Beda Nyata Terkecil, BNT $(\mathrm{LSD}=$ Least Significant Difference) .

$$
\begin{aligned}
& \mathrm{BNT} \alpha=\mathrm{t}_{\alpha(\mathrm{v}) .} \sqrt{ } 2 \mathrm{KTG} / \mathrm{r} \\
& \mathrm{KTG}=0,019 \\
& \mathrm{r}_{\mathrm{A}}=8 ; \mathrm{r}_{\mathrm{B}}=6 ; \mathrm{r}_{(\mathrm{AB})}=2 \\
& \mathrm{t}_{0,05(12)}=2,179 \\
& \mathrm{BNT}_{0,05(\mathrm{~A})}=2,179 \times 0,069=0,150 \\
& \mathrm{BNT}_{0,05(\mathrm{~B})}=2,179 \times 0,079=0,173 \\
& \mathrm{BNT}_{0,05(\mathrm{AB})}=2,179 \times 0,138=0,300 \\
& \quad \mathrm{Uji} \mathrm{BNT}_{0,05} \text { pengaruh utama dan }
\end{aligned}
$$

tunggal dari faktor perlakuan finishing (A) dan media pendingin (B) terhadap laju korosi spesimen didapatkan sebagai berikut :

Tabel 4

Hasil Uji BNT 0,05

\begin{tabular}{|c|c|c|c|c||}
\hline \multirow{2}{*}{$\begin{array}{c}\text { PENGARUH } \\
\text { TUNGGAL, B }\end{array}$} & \multicolumn{3}{|c|}{ PENGARUH TUNGGAL, A } & \multirow{2}{*}{$\begin{array}{c}\text { PENGARUH } \\
\text { UTAMA, B }\end{array}$} \\
\cline { 2 - 4 } B1 & $0,794 \mathrm{c}$ & $0,787 \mathrm{c}$ & $0,098 \mathrm{a}$ & $0,560 \mathrm{~b}$ \\
\hline B2 & $0,352 \mathrm{ab}$ & $0,210 \mathrm{a}$ & $0,212 \mathrm{a}$ & $0,258 \mathrm{a}$ \\
\hline B3 & $0,142 \mathrm{a}$ & $0,118 \mathrm{a}$ & $0,143 \mathrm{a}$ & $0,134 \mathrm{a}$ \\
\hline B4 & $0,289 \mathrm{a}$ & $0,283 \mathrm{a}$ & $0,211 \mathrm{a}$ & $0,261 \mathrm{ab}$ \\
\hline $\begin{array}{c}\text { PENGARUH } \\
\text { UTAMA, } \mathbf{A}\end{array}$ & $0,394 \mathrm{c}$ & $0,350 \mathrm{~b}$ & $0,166 \mathrm{a}$ & \\
\hline
\end{tabular}

Keterangan : Angka-angka yang diikuti oleh huruf yang sama pada kolom yang sama berarti berbeda tidak nyata.

\section{Kesimpulan hasil uji $\mathrm{BNT}_{0,05}$ :}

a. Untuk pengaruh utama $\mathrm{B}$, yakni media pendingin $\mathrm{B} 1$ menunjukkan perbedaan yang nyata (pada taraf uji $5 \%$ ) terhadap laju korosi spesimen dan mempunyai laju korosi rata-rata tertinggi. Sedangkan antara B2, B3 dan B4 tidak menunjukkan perbedaan yang nyata. Laju korosi terendah (ketahanan korosi terbaik) yaitu pada B3 (Pendingin Oli + Air Seer)

b. Untuk pengaruh utama A, yakni perlakuan finishing $\mathrm{A} 1, \mathrm{~A} 2$ dan $\mathrm{A} 3$ masing-masing menunjukkan perbedaan yang nyata (pada taraf uji 5 \%) terhadap laju korosi spesimen dan diperoleh laju korosi terendah (ketahanan korosi terbaik) yaitu pada A3 (pelapisan krom). Sedangkan spesimen yang mempunyai laju korosi tertinggi adalah spesimen dengan perlakuan Al (finishing kasar).

c. Kombinasi perlakuan terbaik (laju korosi terendah) yaitu kombinasi A3B1 (pendingin Air + Air Seer dan pelapisan krom). Secara statistik kombinasi $\mathrm{A} 3 \mathrm{~B} 1$ tidak berbeda nyata dengan A3B2, A3B3, A3B4, A2B2, A2B3, A2B4, A1B2, A1B3, A1B4. 


\section{Analisis Biaya Produksi}

Karena sulitnya mendapat data tentang biaya tetap (fixed cost), sehingga biaya produksi disini hanya mengarah pada biaya variabel (variable cost) yang meliputi biaya bahan baku, tenaga kerja dan lain-lain.

Tabel 5

Biaya Produksi Satu Produk Pisau Dapur

\begin{tabular}{|c|l|r|c|c|}
\hline NO & \multicolumn{1}{|c|}{ URAIAN } & JUMLAH (Rp) & PERSEN & KET. \\
\hline \hline 1 & Bahan baku & 750,00 & 23 & \\
\hline 2 & Tenaga kerja & $1.700,00$ & 52 & \\
\hline 3 & Bahan bakar & 350,00 & 11 & \\
\hline 4 & Pegangan kayu & 200,00 & 6 & \\
\hline 5 & Cincin besi & 200,00 & 6 & \\
\hline 6 & Transportsi & 50,00 & 2 & \\
\hline & Jumlah & $3.250,00$ & 100 & \\
\hline 7 & Pelapisan krom & $2.500,00$ & 77 & \\
\hline & Jumlah & $5.750,00$ & & \\
\hline
\end{tabular}

\section{Percobaan Korosi}

Hasil analisa data dengan menggunakan analisa varian (anava) dua faktor atau dua arah (two way anova) menunjukkan bahwa baik faktor perlakuan variasi finishing maupun faktor variasi pendingin menyebabkan perbedaan laju korosi yang sangat nyata (Fhit. $\gg$ Ftab $1 \%$ ). Atau dengan kata lain bahwa perlakuan variasi finishing dan media pendingin berpengaruh sangat nyata terhadap laju korosi spesimen pisau dapur. Hasil analisa varian juga menunjukkan adanya interaksi antara kedua faktor (Fhit $>$ Ftab.).

Dari uji lanjutan menggunakan uji Beda Nyata Terkecil $\left(\mathrm{BNT}_{0,05}\right)$ bahwa ;

a. Untuk pengaruh utama B, yakni media pendingin $\mathrm{B} 1$ menunjukkan perbedaan yang nyata (pada taraf uji $5 \%$ ) terhadap laju korosi spesimen dan mempunyai laju korosi rata-rata tertinggi. Sedangkan antara B2, B3 dan B4 tidak menunjukkan perbedaan yang nyata. Laju korosi terendah (ketahanan korosi terbaik) yaitu pada B3
(Pendingin Oli + Air Seer). Perlakuan B1 (pendinginan air + air seer) mempunyai laju korosi rata-rata tertinggi, hal ini dimungkinkan karena air seer bersifat asam dan konsentrasinya tidak terlalu tinggi dibanding perlakuan B2 (air seer tanpa air), sehingga justru akan lebih mempercepat terjadinya korosi pada permukaan spesimen.

b. Untuk pengaruh utama A, yakni perlakuan finishing $\mathrm{A} 1, \mathrm{~A} 2$ dan $\mathrm{A} 3$ masing-masing menunjukkan perbedaan yang nyata (pada taraf uji 5 $\%$ ) terhadap laju korosi spesimen dan diperoleh laju korosi terendah (ketahanan korosi terbaik) yaitu pada A3 (pelapisan krom). Sedangkan spesimen yang mempunyai laju korosi tertinggi adalah spesimen dengan perlakuan Al (finishing kasar).

c. Perlakuan A3 (pelapisan krom) yang terbaik karena lapisan krom yang menutupi permukaan spesimen berfungsi sebagai pelindung dari zat 
korosif, sehingga spesimen yang dilapisi krom mempunyai ketahanan korosi yang lebih tinggi. Korosi baru terjadi jika lapisan krom pada permukaan tersebut terkelupas, tergores atau bila terdapat lubang yang memungkinkan zat korosif masuk melalui lubang tersebut.

d. Kombinasi perlakuan terbaik (laju korosi terendah) yaitu kombinasi A3B1 (pendingin Air + Air Seer dan pelapisan krom). Walaupun secara statistik kombinasi A3B1 tidak berbeda nyata dengan A3B2, A3B3, A3B4, $\mathrm{A} 2 \mathrm{~B} 2, \mathrm{~A} 2 \mathrm{~B} 3, \mathrm{~A} 2 \mathrm{~B} 4, \mathrm{~A} 1 \mathrm{~B} 2, \mathrm{~A} 1 \mathrm{~B} 3$, A1B4. Hal ini telah sejalan dengan apa yang dihasilkan pada point $a$ dan $b$ diatas, bahwa untuk pengaruh utama $\mathrm{B}$, perlakuan Bl merupakan perlakuan terbaik karena dapat menghasilkan ketahanan korosi yang tertinggi, demikian pula pada perlakuan A3 (pelapisan krom).

\section{Biaya Produksi}

Hasil analisis biaya, diperoleh bahwa biaya produksi untuk satu produk pisau dapur sebesar Rp. 3.250,- (biaya investasi awal belum diperhitungkan), jelas jauh lebih tinggi dibanding beberapa tahun yang lalu sebelum terjadi krisis moneter, sehingga hal ini akan berpengaruh pula pada penentuan harga jual dan tidak menutup kemungkinan akan mengalami sedikit pergeseran pangsa pasar. Akibat lainnya akan sulit bisa bersaing di pasar, terutama dengan produk-produk industri besar.
Pelapisan krom pada produk yang bertujuan agar penampilan lebih bagus dan lebih tahan terhadap korosi, sehingga akan lebih berdaya saing, ternyata diikuti pula konsekuensi tambahan biaya yang cukup besar yaitu $77 \%$ dari biaya produksi. Disamping itu, pelapisan krom akan mengurangi ketajaman pada pisau, sehingga pelapisan krom hanya direkomendasikan untuk produk-produk dekoratif atau produk yang tidak diperlukan ketajamannya.

\section{KESIMPULAN}

Berdasarkan analisa yang telah dilakukan, maka kesimpulan yang dapat diambil antara lain :

1. Perlakuan finishing (A) yang berbeda berpengaruh sangat nyata terhadap laju korosi spesimen. Hasil analisis lanjutan dengan uji Beda Nyata Terkecil (BNT), diperoleh bahwa laju korosi terendah pada perlakuan A3 (pelapisan krom)

2. Media pendingin (B) yang berbeda berpengaruh sangat nyata terhadap laju korosi spesimen. Hasil analisis lanjutan dengan uji Beda Nyata Terkecil (BNT), diperoleh bahwa laju korosi terendah pada perlakuan B1 (air+air seer).

3. Ada interaksi antara faktor A (finishing) dan faktor B (media pendingin). Hasil analisis lanjutan dengan uji Beda Nyata Terkecil (BNT), diperoleh bahwa kombinasi terbaik (laju korosi terendah) yaitu A3B1 (pelapisan krom dan media pendingin air + air seer). 
4. Hasil perhitungan biaya produksi (hanya variable cost) sebesar Rp. 3.250 ,- setiap produk. Jika dilakukan pelapisan krom untuk meningkatkan sifat dekoratif dan ketahanan korosinya, sehingga lebih berdaya saing, diperkirakan memerlukan tambahan biaya sebesar Rp. 2.500,setiap produk atau perlu tambahan sebesar $77 \%$ dari biaya produksi.

\section{DAFTAR PUSTAKA}

Breck, W.G., et.al., 1989, Chemistry for Science and Engineering, $2^{\text {nd }}$

Edition, Mc Graw Hill Book Co., Singapore.

Fontana, M.G., 1986, Corrosion Engineering, $3^{\text {rd }}$ Edition, Mc Graw Hill, Ohio.

Hanafiah, K.A., 1995, Rancangan Percobaan, FP-UNSRI, RGP, Jakarta.

Hartomo, A.J. \& Kaneko, T., 1995, Mengenal Pelapisan Logam, Andi Offset, Yogyakarta.

Mubin, A. \& Moh. Jufri, 1997, Pengaruh penambahan inhibitor organik terhadap korosi baja ST 37 dalam larutan asam dan garam,
Mubin, Ahmad, 1998, Proses Pelapisan krom keras pada permukaan logam dan ketahanan korosinya dalam lingkungan asam, Lap. Penelitian, FT-UMM, Malang.

Sanders, A.H., 1950, Electroplating, International texbook company, Great Britain.

Shreir, L.L., 1976, Corrosion, $2^{\text {nd }}$ Edition, Newnes-Butterworth, Boston.

Smallman, R.E. 1991, Metalurgi Fisik

Modern (Alihbahasa : Sriati Dj),

Edisi ke-4, PT. Gramedia, Jakarta.

Smith, W.F., 1986, Principle of Materials

Science and Engineering, Mc Graw Hill Inc.

Surdia, T. \& Saito, S., 1985, Pengetahuan Bahan Teknik, PT. Pradnya Paramita, Jakarta.

Walpole, R.E. \& Myers R.H., 1995, Ilmu Peluang dan Statistika untuk Insinyur dan Ilmuwan (alihbahasa : RK. Sembiring), Edisi Ke-4, ITB, Bandung. 